\title{
Potencijal i uloga biomase u hrvatskoj i europskoi energetskoj tranziciji
}

\section{Potential and Role of Biomass in Croatian and European Energy Transition}

Review paper $\bullet$ Pregledni rad

Received-prispjelo: 5. 5. 2020.

Accepted-prihvaćeno: 14. 1. 2021.

UDK: $630 * 831.1$

https://doi.org/10.5552/drvind.2021.2023

(C) 2021 by the author(s). Licensee Faculty of Forestry and Wood Technology, University of Zagreb. This article is an open access article distributed under the terms and conditions of the Creative Commons Attribution (CC BY) license.

SAŽETAK • Republika Hrvatska kao punopravna članica Europske unije trenutačno sudjeluje u energetskoj tranziciji, odnosno u procesu dekarbonizacije gospodarstva transformacijom energetskog sektora u kojemu obnovljivi izvori energije zamjenjuju fosilna goriva. U tom procesu biomasa kao najsloženiji oblik obnovljive energije ima važnu ulogu s obzirom na brojne pozitivne okolišne i ekonomsko-socijalne aspekte uporabe. Sukladno ciljevima EU-a, Hrvatska je ostvarila potrebnih $20 \%$ udjela proizvodnje iz obnovljivih izvora, no udio proizvodnje energije iz biomase još nije zadovoljavajući. Najiskorištavaniji izvor biomase jest kruta biomasa, posebice peleti, proizvođači kojih su izvozno orijentirani. Unatoč tome, Hrvatska još uvijek ovisi o uvozu biomase, kao i sve članice EU-a. Stoga je za unapređenje proizvodnje i potrošnje energije od biomase potrebna sinergija i zajedničko djelovanje svih sudionika energetskog sektora, a donositelji odluka odgovarajućim mjerama trebaju stvoriti preduvjete za razvoj tržišta biomase. U ovom se radu na temelju analize tržišta biomase te njezine uloge u nacionalnim i europskim energetskim politikama analizira trenutačni položaj i značenje biomase u energetskoj tranziciji Hrvatske. Na temelju provedenog istraživanja može se zaključiti da je jasno vidljiv pomak prema niskougljičnoj energetici, u čemu upravo biomasa ima važnu ulogu, iako je stopa upotrebe biomase u Hrvatskoj još uvijek ispod ambicioznog scenarija koji predviđa EU.

Ključne riječi: biomasa; energetska tranzicija; Hrvatska; Europska unija; Europski zeleni plan

\begin{abstract}
The Republic of Croatia, as a full member of the European Union, is currently participating in the energy transition, i.e. the process of decarbonization of the economy through the transformation of the energy sector in which renewable energy sources replace fossil fuels. In this process, biomass as the most complex form of renewable energy plays an important role given the many positive environmental and economic-social aspects of use. In accordance with the goals of the European Union, Croatia has achieved the required 20 percent share of production from renewable sources, but the share of energy production from biomass is still unsatisfactory. The most commonly used sources of biomass are solid biomass, especially pellets whose producers are export-oriented. Nevertheless, Croatia is still dependent on biomass imports, as is the case at EU level. Therefore, the improvement of production and consumption of energy from biomass requires synergy and joint action of all stakeholders in the energy sector, and decision-makers should create appropriate preconditions for the development of the biomass market. This paper analyzes the current position and importance of biomass in the energy transition of Croatia, based on the analysis of the biomass market, and its position in national and European energy policies. The research concludes that, although the rate of biomass use in Croatia is still below the ambitious scenario envisaged by the European Union, there is a clear shift towards low-carbon energy in which biomass plays a significant role.
\end{abstract}

Keywords: biomass; energy transition; Croatia, European Union; European Green Deal

\footnotetext{
Author is a former student of the Faculty of Economics and Business Zagreb, Zagreb, Croatia.

${ }^{2}$ Author is a senior research associate at the Economic Research Division in Croatian Academy of Sciences and Arts, Zagreb, Croatia.
} 


\section{UVOD}

\section{INTRODUCTION}

Nova industrijska strategija Europske unije (EU), četvrta industrijska revolucija (4IR), zelena i kružna ekonomija te bioekonomija, energetska tranzicija, resursna učinkovitost i klimatska neutralnost najvažnije su sastavnice novoga industrijskog doba koje obilježavaju gospodarske, društvene i okolišne promjene te tehnološka otkrića. Da bi tu viziju nove industrijske ere pretvorila u stvarnost, Europa će trebati upravljati brzom i sveobuhvatnom transformacijom, boriti se za globalnu konkurentnost i baviti se niskougljičnom energijom i sirovinama, što će zahtijevati djelovanje i suradnju donositelja politika na svim razinama. Prema Europskoj komisiji, Europski zeleni plan nudi rješenja za ta pitanja (EK, 2019a). Riječ je o novoj strategiji rasta kojom se EU nastoji preobraziti u pravedno i prosperitetno društvo s modernim, resursno učinkovitim i konkurentnim gospodarstvom u kojemu 2050. neće biti netoemisija stakleničkih plinova i u kojemu gospodarski rast nije povezan s iskorištavanjem resursa (EK, 2019a). Ambicije se neće moći ostvariti bez strateškog pristupa obnovljivim izvorima energije (OIE).

Naime, obnovljiva energija jedan je od ključnih prioriteta energetske unije (EK, 2019b), a OIE-ovi imaju središnju ulogu upravo u Europskome zelenom planu (EK, 2019a). U tom je kontekstu Direktiva 2009/28/EZ o promicanju uporabe energije iz obnovljivih izvora (RED I) bila osnovni element politike Energetske unije i ključni pokretač na putu ostvarenja ciljeva obnovljive energije do 2020. (EK, 2019b). Međutim, stupanjem na snagu Direktive (EU) 2018/2001 o promicanju uporabe energije iz obnovljivih izvora (RED II) u prosincu 2018. uspostavljen je novi okvir za ostvarivanje obvezujućeg cilja EU-a od najmanje $32 \%$ obnovljive energije u konačnoj brutopotrošnji energije do 2030. godine. Prema važećoj Direktivi, ,povećana uporaba energije iz obnovljivih izvora ima glavnu ulogu u promicanju sigurnosti opskrbe energijom, održive energije po pristupačnim cijenama, tehnološkog razvoja i inovacija te tehnološkog i industrijskog vodstva, osiguravajući pritom okolišne, društvene i zdravstvene koristi te važne mogućnosti za zapošljavanje i regionalni razvoj, ponajprije u ruralnim i udaljenim područjima“. Osim toga, OIE-ovi su usko povezani s energetskom učinkovitošću, pokretač su dekarbonizacije energetskog sustava Unije i izvor gospodarskog rasta, pridonose smanjenju onečišćenja zraka te zbog njih ekonomije država članica Unije imaju lakši pristup povoljnoj i čistoj energiji (EK, 2017).

$\mathrm{Na}$ tom tragu osmišljen je i treći cilj ažurirane europske biogospodarske strategije - „Održivo biogospodarstvo za Europu: Jačanje veze gospodarstva, društva i okoliša“ (engl. A sustainable Bioeconomy for Europe: Strengthening the connection between economy, society and the environment) (EK, 2018a), prema kojemu je smanjenje ovisnosti o neobnovljivim, neodrživim resursima, bilo iz domaćih izvora ili iz uvoza, važno za postizanje energetskih i klimatskih ciljeva EU-a jer se očekuje da će ključna sastavnica u kombinaciji izvora energije 2030. ostati bioenergija, na koju trenutačno otpada najveći udio energije iz obnovljivih izvora u EU-u. Nadalje, prema Europskoj komisiji (2019b), glavni OIE-ovi koji su 2017. iskorištavani u potrošnji energije bili su biomasa u sektoru grijanja i hlađenja, hidroenergija i energija vjetra u sektoru električne energije te biogoriva u sektoru prometa. O važnosti biomase svjedoči i činjenica da su prema Strategiji pametne specijalizacije Republike Hrvatske (NN, 32/2016) upravo biomasa i bioproizvodi glavni inovacijski pokretači na znanju utemeljene bioekonomije. Osim toga, područje biomase otvara razvojne mogućnosti određenim industrijskim sektorima koje će trebati usmjeriti prema različitim nišama i novim tehnološkim smjerovima (NN, 32/2016), a prema procjenama sektora, u industrijama EU-a u kojima se pretežito koristi biomasa moglo bi se do 2030. otvoriti milijun novih radnih mjesta (EuropaBio, 2016.).

Nadalje, prema Zakonu o obnovljivim izvorima energije i visokoučinkovitoj kogeneraciji (NN 100/2015), biomasa se definira kao biorazgradivi dio proizvoda, otpada i ostataka biološkog podrijetla iz poljoprivrede (uključujući tvari biljnoga i životinjskog podrijetla), šumarstva i srodnih proizvodnih djelatnosti, uključujući ribarstvo i akvakulturu, kao i biorazgradivi dio industrijskoga i komunalnog otpada. Sukladno definiciji, ,,biomasa ima golem potencijal za daljnji razvoj koji treba slijediti neka osnovna načela, kao što su visoka učinkovitost, konkurentnost i održivost“", a ,korištenje biomase za proizvodnju topline na najbolji način zadovoljava navedene principe" (Šegon et al., 2014.). U tom smislu Republika Hrvatska (RH) ima snažan potencijal za iskorištavanje biomase za energetske namjene, što se može zaključiti iz sve većeg broja projekata s primjenom biomase u proizvodnji električne i toplinske energije. Raste broj kogeneracijskih postrojenja i elektrana na biomasu koje svojom proizvodnjom toplinske energije opskrbljuju i javne ustanove $u$ svojoj blizini, a radi se i na projektima kojima se kućanstva potiču na zamjenu starih kotlova kotlovima na biomasu, čime se jača svijest o važnosti obnovljivih izvora energije i energetske učinkovitosti.

Trenutačno su EU-u $i$ većina država članica na dobrom putu da ostvare svoje obvezujuće ciljeve za 2020. (Eurostat, 2020.). Međutim, europska je industrija izgubila svoj položaj u razvoju OIE-ova. U svijetu je porast proizvodnje obnovljive energije ponajprije posljedica agresivne proizvodnje solarnih panela $u$ Kini (po dampinškim cijenama). Naime, iako je Europa rano zauzela (a Kina poslije preuzela) vodeću ulogu u razvoju solarnih panela i ćelija, o čemu svjedoči činjenica da je pet europskih tvrtki bilo među najvećim proizvođačima od 2001. do 2004., u međuvremenu se situacija promijenila (Bjerkem et al., 2019.). Očekuje se da će do 2022. na SAD, Indiju i Kinu otpadati dvije trećine globalnog širenja OIE-ova. Osim toga, Kina je i u hidroenergetici, bioenergiji i električnim vozilima vodeća zemlja na globalnom tržištu (Bjerkem et al., 2019). Stoga je neupitna važnost ekonomske analize OIE-ova, a time i biomase. 


\section{BIOMASA U SKLOPU EUROPSKOGA ENERGETSKOG OKVIRA \\ 2 BIOMASS WITHIN EUROPEAN ENERGY FRAMEWORK}

U sektoru energije iz obnovljivih izvora u Europi je zaposleno više od 1,1 milijuna osoba, a najveći su poslodavci industrija za proizvodnju energije od vjetra, solarnih fotonaponskih tehnologija i krute biomase (EK, 2016.). Naime, nastojanja EU-a da do 2020. postigne svoje energetske i klimatske ciljeve rezultirala su novim industrijama, radnim mjestima u Europi i većim tehnološkim inovacijama, što je smanjilo troškove tehnologije, a kao najbolji primjer Europska komisija (2018b) navodi upravo ,revoluciju u području energije iz obnovljivih izvora“". Stoga je u posljednjih desetak godina usvojen niz komunikacija, strategija, direktiva i akcijskih planova ,u kontekstu vodstva EU-a u prijelazu na pametniju i čišću energiju za sve i provedbe Pariškog sporazuma“ (EK, 2016.).

Kronološki, u skladu s čl. 194. st. 1. Ugovora o funkcioniranju Europske unije (UFEU), promicanje obnovljivih oblika energije jedan je od ciljeva energetske politike Unije. Nadalje, kao jedan od prvih konkretnih koraka, Direktivom 2009/28/EZ uspostavljen je regulatorni okvir za promicanje uporabe energije iz obnovljivih izvora. Njime je utvrđen obvezujući nacionalni cilj glede udjela obnovljive energije u potrošnji energije i u sektoru prometa koji je trebao biti postignut do 2020. Zatim je u ožujku 2010. objavljen dokument ,Europa 2020: strategija za pametan, održiv i uključiv rast" (EK, 2010.). U toj strategiji Komisija predlaže sedam vodećih inicijativa za postizanje napretka u svakoj od prioritetnih tema, među ostalim za resursno učinkovitu Europu koja je podrazumijevala „smanjenje emisije stakleničkih plinova za najmanje $20 \%$ u odnosu na razinu iz 1990. ili za $30 \%$, ako su uvjeti dobri; povećanje udjela OIE u krajnjoj potrošnji energije na $20 \%$; i povećanje energetske učinkovitosti za $20 \%$ ".

Potom je 2011. usvojen „Plan za prijelaz na konkurentno niskougljično gospodarstvo do 2050.“ (engl. A Roadmap for moving to a competitive low carbon economy in 2050), a u lipnju 2012. donesena je komunikacija pod nazivom „Obnovljiva energija: važan čimbenik na europskom energetskom tržištu“ (engl. Renewable Energy: a major player in the European energy market), u kojoj su nabrojene mogućnosti za politiku OIE-ova za razdoblje nakon 2020. godine.

Nakon toga je EK u siječnju 2014. donio komunikaciju „Okvir za klimatsku i energetsku politiku u razdoblju 2020. - 2030.“, u kojoj su donesene smjernice za buduću energetsku i klimatsku politiku Unije i u kojoj se promišlja o tome kako će se te politike razvijati nakon 2020. Komisija je predložila da bi cilj Unije za 2030. u smislu udjela energije iz obnovljivih izvora potrošene u Uniji trebao iznositi barem 27 \%, a Europsko vijeće taj je prijedlog potvrdilo, što znači su članice trebale odrediti i ambicioznije vlastite nacionalne ciljeve kako bi najprije ostvarile, a potom i nadmašile svoje planirane doprinose cilju Unije za 2030. Nadalje, 2014. jedan je od deset političkih prioriteta tadašnjeg predsjednika EK-a Jeana-Clauda Junckera bila Energetska unija. Na tom je tragu u veljači 2015. EK objavio „Paket mjera za Energetsku uniju - Okvirnu strategiju za otpornu energetsku uniju s naprednom klimatskom politikom" (engl. Energy Union package - A Framework Strategy for a Resilient Energy Union with a ForwardLooking Climate Change Policy). U tom je paketu mjera istaknuto da strategija Energetske unije ima pet usko povezanih dimenzija osmišljenih za postizanje veće energetske sigurnosti, održivosti i konkurentnosti. To su energetska sigurnost, solidarnost i povjerenje, potpuno integrirano europsko energetsko tržište, energetska učinkovitost, dekarboniziranje gospodarstva i istraživanje, inovacije i konkurentnost. Dodatno je naglašeno da EU ima pravila o energiji utvrđena na europskoj razini, ali u praksi postoji 28 nacionalnih zakonodavnih okvira, zbog čega je nužno razvijati integrirano energetsko tržište kako bi se potaknulo tržišno natjecanje i postigla veća učinkovitost tržišta.

Kao sljedeći korak EK je u studenom 2016. objavio komunikaciju naslova „Čista energija za sve Europljane“ (engl. Clean Energy For All Europeans), kojom je predstavio regulatorne prijedloge i mjere za olakšavanje prijelaza na čistu energiju, usmjerene na modernizaciju gospodarstva i poticanje ulaganja u sektore povezane s čistom energijom. Taj paket mjera imao je tri glavna cilja: davanje prioriteta energetskoj učinkovitosti, postizanje globalnog vodstva u području OIE-ova te osiguranje poštenog rješenja za potrošače.

U studenom 2018. objavljena je dugoročna strategija „Čist planet za sve - Europska strateška dugoročna vizija za prosperitetno, moderno, konkurentno i klimatski neutralno gospodarstvo" (engl. A Clean Planet for all-A European strategic long-term vision for a prosperous, modern, competitive and climate neutral economy), čija je svrha ,potvrditi vodeću ulogu Europe u oblikovanju globalne klimatske politike te predstaviti viziju koja može pomoći da se do 2050. na troškovno učinkovit način i putem društveno pravedne tranzicije postigne nulta neto stopa emisija stakleničkih plinova“" (EK, 2018b). Nadalje, EU je krajem 2018. usvojio već spomenutu Direktivu 2018/2001/EU o promicanju uporabe energije iz obnovljivih izvora, čijim je stupanjem na snagu uspostavljen novi okvir za ostvarivanje obvezujućeg cilja Unije od najmanje $32 \%$ obnovljive energije u konačnoj brutopotrošnji energije do 2030. (EK, 2019b). Paralelno je usvojena i Uredba (EU) 2018/1999 Europskog parlamenta i Vijeća o upravljanju Energetskom unijom i djelovanjem u području klime u kojoj se propisuje izrada integriranih nacionalnih energetskih $\mathrm{i}$ klimatskih planova za desetogodišnje razdoblje. Prvi integrirani energetski i klimatski plan trebao bi obuhvatiti razdoblje od 2021. do 2030. godine.

Konačno, prvi važan korak novoizabrane predsjednice EK-a Ursule von der Leyen bio je Europski zeleni plan, nova strategija rasta za postizanje održivoga gospodarstva EU-a, u kojoj je istaknuto da se ,mora razviti energetski sektor koji se uglavnom temelji na obnovljivim izvorima, uz brzo postupno ukidanje upotrebe ugljena i dekarbonizaciju plina“ (EK, 2019a). U sklopu 
Europskoga zelenog plana fokus je stavljen na sedam područja, među ostalim i na čistu energiju. Prema toj bi politici države članice 2023. morale ažurirati svoje nacionalne energetske i klimatske planove koji bi odražavali nove klimatske ambicije (EK, 2019c). Na tom je tragu deset godina nakon „Strategije Europa 2020“, 10. ožujka 2020., objavljena ,Nova industrijska strategija za Europu“ (engl. A New Industrial Strategy for Europe), kojom se želi osigurati klimatska neutralnost i digitalno vodstvo, a kako bi postala konkurentnija, zelenija i kružnija, potrebno je osigurati sigurnu opskrbu čistom i pristupačnom energijom te sirovinama.

Iz opsežnog pregleda europskoga energetskog okvira vidljivo je istodobno povezano djelovanje EU-a na različitim područjima s ciljevima i planovima koji su kroz godine konkretniji, detaljniji i razrađeniji. Osim toga, svaka članica ima svoje nacionalne energetske politike koje su oblikovane upravo na europskom tragu, ali i u skladu s nacionalnim mogućnostima $\mathrm{i}$ interesima.

\section{BIOMASA U HRVATSKOJ ENERGETSKOJ POLITICI \\ 3 BIOMASS WITHIN CROATIAN ENERGY POLICY}

Sudjelovanjem u energetskoj tranziciji EU-a Hrvatska kao punopravna članica mora usklađivati energetsku politiku i zakonodavni okvir sa zakonodavstvom EU-a te ostvarivati svoje interese u području energetike, a oni su utvrđeni strategijom, zakonima i drugim propisima koji se odnose na obavljanje energetske djelatnosti. Međutim, i prije nego što je postala članica EU-a Hrvatska je tijekom pretpristupnih pregovora i priprema za članstvo izradila Program korištenja OIE i Akcijski plan za OIE kako bi utvrdila dugoročnu perspektivu razvoja njihove infrastrukture (u sklopu zatvaranja poglavlja 15. Energetika pretpristupnih pregovora) (Ministarstvo gospodarstva, 2013.), a reforma energetskog sektora u Hrvatskoj započela je donošenjem Zakona o energiji 2001. (NN 68/2001) i paketa energetskih zakona kojima se uređuje obavljanje pojedinih energetskih djelatnosti.

Prema Zakonu o energiji (NN 68/2001 i 177/2004) „osnovni akt kojim se utvrđuje energetska politika i planira energetski razvitak je Strategija energetskog razvoja“ kojom se „utvrđuju nacionalni energetski programi, potrebna ulaganja u energetiku, poticaji za ulaganja u obnovljive izvore i kogeneraciju i za povećanje energetske učinkovitosti te unapređenje mjera zaštite okoliša“, a donosi je Hrvatski sabor na prijedlog Vlade RH za razdoblje ne kraće od deset godina. Do sada je Sabor usvojio tri energetske strategije. Prva od njih - Strategija energetskog razvitka, donesena je 2002. i imala je ,energetsku, ekonomsku, zakonodavnu, organizacijsku, institucionalnu i obrazovnu dimenziju s ciljem da pripremi energetski sektor Hrvatske za što lakše i efikasnije uključivanje u EU“ (NN 38/2002-839).

Međutim, s obzirom na to da je u međuvremenu $\mathrm{RH}$ postala kandidatkinja za punopravno članstvo u
EU, da je prihvatila sporazum o Energetskoj zajednici te potpisala i ratificirala Kyotski protokol uz Okvirnu konvenciju UN-a o promjeni klime te da je bila suočena s velikom nestabilnošću cijena energije na svjetskom tržištu, 2009. usvojena je druga, unaprijeđena strategija - Strategija energetskog razvoja $\mathrm{RH}(\mathrm{NN}$ 130/2009-3192), koja je imala tri osnovna cilja: sigurnost opskrbe energijom, konkurentnost energetskog sustava i održivost energetskog razvoja. Prema toj Strategiji (NN 130/2009-3192), Hrvatska pripada zemljama s velikim potencijalom biomase te je sebi postavila cilj da u 2010. iskorištava oko 15 PJ energije iz biomase, a u 2020. oko 26 PJ. Predviđeno je da će se dio te biomase upotrebljavati u brojnim elektranama na biomasu ukupne snage oko 85 MW u 2020, , a radi povećanja energetske učinkovitosti prednost $\boldsymbol{c} e$ imati postrojenja $\mathrm{s}$ istodobnom proizvodnjom električne $\mathrm{i}$ toplinske energije. Tom je Strategijom (NN 130/2009-3192) predviđeno i sinergijsko djelovanje razvojnih politika nekoliko ministarstava putem poticajnih mjera državne, industrijske, poljoprivredne i energetske politike kojima će se omogućiti razvoj hrvatske drvoprerađivačke industrije, gospodarenje šumama $\mathrm{i}$ iskorištavanje šumske biomase te poticati pošumljavanje i uzgajanje kultura kratkih ophodnji, kao i uporaba biomase u proizvodnji električne i toplinske energije u kogeneracijama i elektranama na biomasu.

Nakon što je 1. srpnja 2013. pristupila EU-u, RH je, zajedno s drugim članicama, preuzela obvezu povećanja potrošnje energije iz obnovljivih izvora, u skladu s Direktivom 2009/28/EZ o poticanju uporabe energije iz obnovljivih izvora, prema kojoj bi u 2020. udio energije iz OIE-ova u neposrednoj bruto potrošnji na razini EU-a trebao iznositi najmanje $20 \%$. Kako bi se taj cilj ostvario, svaka je članica morala donijeti nacionalni akcijski plan za OIE-ove u kojemu se određuje ukupni nacionalni cilj vezan za OIE-ove (Ministarstvo gospodarstva, 2013.). U skladu s tim, Hrvatska je Nacionalni akcijski plan za OIE do 2020. godine usvojila 2013.

Potom je Ministarstvo zaštite okoliša i energetike RH započelo izradu treće Strategije energetskog razvoja Republike Hrvatske do 2030., s pogledom na 2050. godinu. Sukladno smjernicama Povjerenstva za izradu Strategije, Energetski institut „Hrvoje Požar“izradio je Zelenu i Bijelu knjigu (2019a i 2019b), koje su bile analitička podloga za izradu Strategije. U skladu s navedenim, u svibnju 2019. objavljeni su Nacrt prijedloga Strategije i Strateška studija utjecaja na okoliš (Ministarstvo zaštite okoliša i energetike, 2019a i 2019b). Na postojeće nacionalne strategije i planove nadovezuje se i Integrirani nacionalni energetski i klimatski plan za razdoblje od 2021. do 2030. godine, u kojemu se daje pregled nacionalnih ciljeva za svaku od pet ključnih dimenzija Energetske unije te odgovarajuće politike i mjere za ostvarivanje tih ciljeva (Ministarstvo zaštite okoliša i energetike, 2019c).

Konačno, 28. veljače 2020. usvojena je Strategija energetskog razvoja RH do 2030., s pogledom na 2050. godinu (NN 25/2020-602), prema kojoj iskorištavanje biomase dobiva novi kontekst s kružnim gospodarstvom i biogospodarstvom te se potražnja za bioma- 
som kao sirovinom proširuje iz dotadašnjih vrijednosti na nove, inovativne dobavne lance i proizvode utemeljene na biološkoj osnovi. Poljoprivreda, šumarstvo i ribarstvo te industrije utemeljene na tim sektorima, kao i održavanje krajolika (prometnih, energetskih i ostalih infrastruktura, vodotokova, urbanih zelenih površina), uz gospodarenje otpadom, čine sirovinsku osnovu obnovljivih bioloških resursa biogospodarstva ili biomasu. Pri tome bi prednost $\mathrm{u}$ iskorištavanju biomase trebalo dati proizvodima s većom dodanom vrijednosti ili primjenom kaskadnog korištenja, ali i uskladiti s nacionalnim kapacitetom gospodarstva i sa znanstvenoistraživačkom zajednicom te sa strateškim razvojnim ciljevima.

Na energetski sektor, pa tako i na OIE-ove i biomasu, uvelike utječe Zakon o obnovljivim izvorima energije i visokoučinkovitoj kogeneraciji iz 2015. (NN 100/2015) te izmjene i dopune Zakona koje su stupile na snagu krajem 2018. (NN 111/2018). Donošenjem tog Zakona Hrvatska je prvi put na jednome mjestu uredila područje OIE-ova i time potvrdila da su iskorištavanje obnovljivih izvora i proizvodnja energije iz visokoučinkovitih kogeneracija važni za nacionalno gospodarstvo. Navedenim Zakonom te njegovim izmjenama i dopunama utvrđene su i mnogobrojne prednosti za investitore olakšavanjem razumijevanja procesa izgradnje proizvodnih postrojenja i ulaskom u sustav poticanja, čime se omogućuje veća transparentnost $i$ bolja informiranost svih sudionika na tržištu.

Jedan od aktualnih zakona u RH jest i Zakon o drvenastim kulturama kratkih ophodnji (NN 15/2018313), usvojen 2018. radi stvaranja uvjeta za proizvodnju biomase iz kultura kao obnovljivoga i ekološki prihvatljivog energenta na načelima gospodarske održivosti, socijalne odgovornosti i ekološke prihvatljivosti. Taj je Zakon prvi takav propis u Hrvatskoj, a njegovom se primjenom stvara mogućnost za iskorištavanje šumskih i poljoprivrednih zemljišta koja nisu pogodna za poljoprivrednu proizvodnju ili su zapuštena. Time se potiče razvoj zemljišta kao resursa za proizvodnju energije i stvara dodana vrijednost, ali i otva- raju nova radna mjesta putem samozapošljavanja i zapošljavanja u ruralnim područjima.

\section{ANALIZA HRVATSKOG TRŽIŠTA BIOMASE U USPOREDBI S TRŽIŠTEM EUROPSKE UNIJE \\ 4 ANALYSIS OF CROATIAN BIOMASS MARKET IN RELATION TO EUROPEAN UNION MARKET}

Posljednjih je godina iskorištavanje OIE-ova u zemljama EU-a u snažnom porastu, što se ponajprije može pripisati programu Strategije Europa 2020. (prema kojoj je jedan od utvrđenih obveznih ciljeva povećanje udjela OIE-ova u potrošnji energije u EU-u na 20 \%) i Direktivi o energiji iz obnovljivih izvora, usvojenoj 2009. (kojom su za svaku državu utvrđeni nacionalni ciljevi u području energije iz obnovljivih izvora uzimanjem u obzir njihove polazišne točke i ukupnog potencijala za energiju iz obnovljivih izvora). Napredak u ostvarenju tih ciljeva vidljiv je na slici 1 ., koja prikazuje koliko je opsežna upotreba obnovljive energije te stupanj do kojega su obnovljiva goriva zamijenila fosilna $\mathrm{i}$ time pridonijela dekarbonizaciji europskoga gospodarstva.

Hrvatska je svoj cilj od $20 \%$ ostvarila još 2004 ., kada je bila četvrta članica po visini udjela energije iz obnovljivih izvora u bruto finalnoj potrošnji. Taj je udio 2017. porastao na 27,28 \%, a i tada je Hrvatska po visini udjela i dalje ostala među prvih deset zemalja članica, i to na osmome mjestu. Prema podatcima Eurostata za 2018., udio energije iz obnovljivih izvora iznosio je $28 \%$, te je Hrvatska ponovo zauzela osmo mjesto među zemljama članicama EU-a. Ako se takav rast potrošnje energije iz obnovljivih izvora nastavi i u idućem razdoblju, Hrvatska ne bi trebala imati poteškoća u ostvarivanju ciljeva za iduće desetljeće. Osim toga, hrvatska proizvodnja i potrošnja energije iz drva i biomase posljednjih godina ostvaruju porast, iako niskom prosječnom godišnjom stopom. Prema podatcima Energetskog instituta „Hrvoje Požar“, u razdoblju

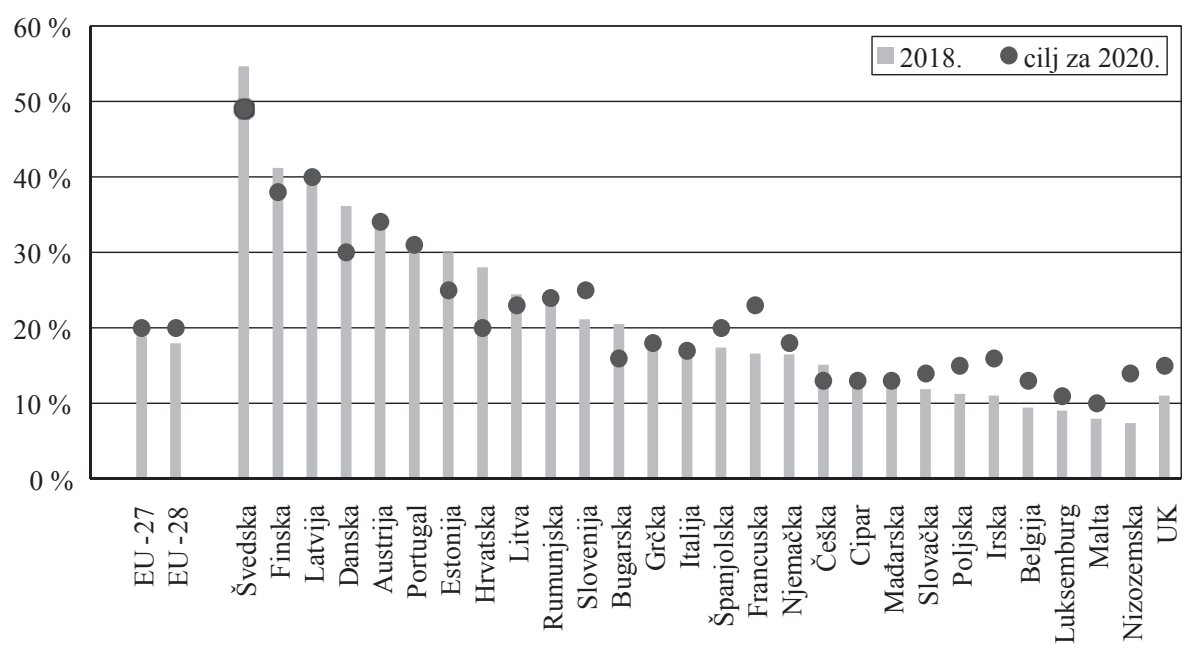

Slika 1. Udio energije iz obnovljivih izvora unutar EU-28 u 2018. godini u bruto finalnoj potrošnji (Eurostat) Figure 1 Share of renewable energy in EU28 in 2018 in gross final consumption (Eurostat) 


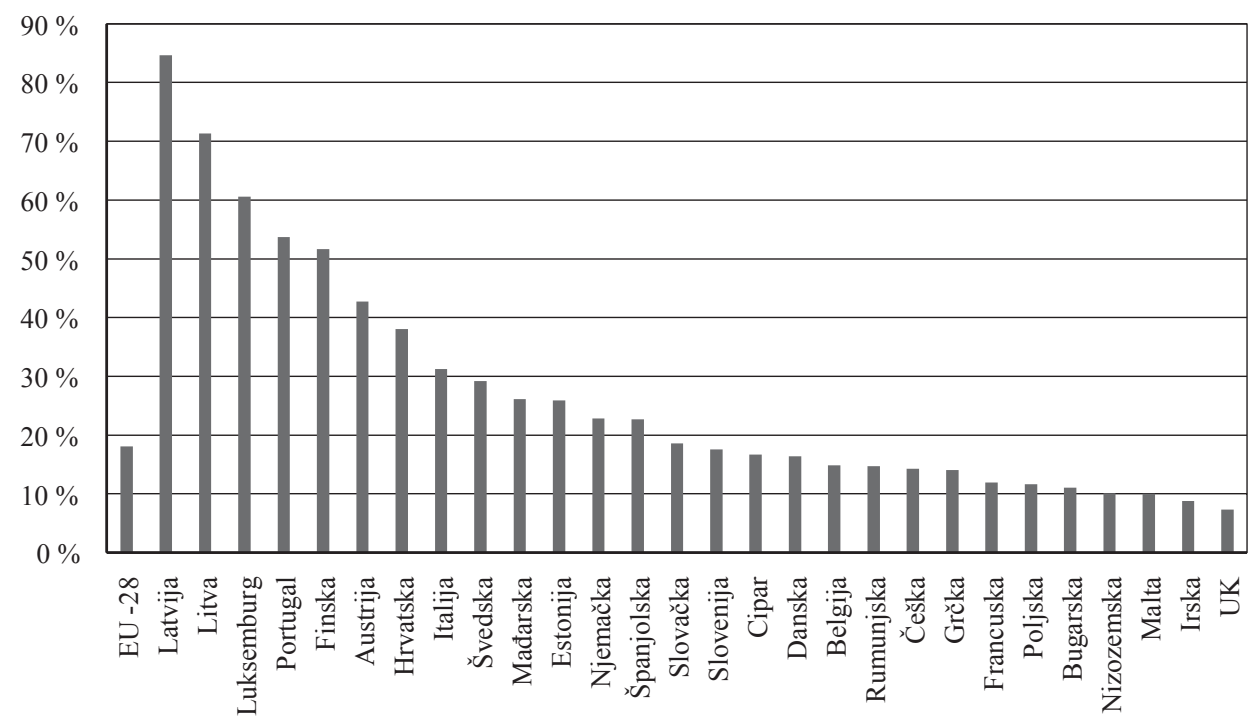

Slika 2. Udio proizvedene primarne energije iz biomase i obnovljivog otpada u ukupnoj proizvodnji primarne energije zemalja EU-28 u 2017. (izračun autorica prema podatcima Eurostata i udruge Bioenergy Europe)

Figure 2 Share of primary energy produced from biomass and renewable waste in total primary energy production of EU28 in 2017 (calculation by authors according to Eurostat and Bioenergy Europe)

2013. - 2018. ostvaren je porast proizvodnje s prosječnom godišnjom stopom od $0,5 \%$ te porast potrošnje s prosječnom godišnjom stopom od $0,6 \%$. Unatoč porastu proizvodnje, Hrvatska u proizvodnji primarne energije iz biomase ima vrlo mali udio s obzirom na razinu EU-a (Energetski institut „Hrvoje Požar“, 2019c). Tako je 2016. udio proizvodnje primarne energije iz biomase i obnovljivog otpada u usporedbi s EU-om, prema podatcima Bioenergy Europe (Statistical Report, 2018 Edition), iznosio 1,17\%. Kao dominantan izvor biomase pojavljuje se kruta biomasa, a sve veću važnost dobiva proizvodnja peleta, koja ostvaruje stalni trend rasta. Energija iz biomase prevladava u općoj potrošnji, dok je u industriji i sektoru prometa biomasa, odnosno biogorivo još uvijek najslabije iskorištavan energent u neposrednoj potrošnji. Uvoz i izvoz biomase ostvaruju stabilan trend rasta, iako uvoz ostvaruje veću prosječnu godišnju stopu rasta od izvoza. Ista je situacija i na razini EU-a, koji još uvijek uvelike ovisi o uvozu goriva, pa tako i o uvozu biomase.

Kad je riječ o potrošnji energije iz obnovljivih izvora, podatci Europske udruge za biomasu Bioenergy Europe (Statistical Report, 2019.) pokazuju da je na razini EU-a 2017. biomasa činila 8,6 \% ukupne bruto finalne potrošnje EU-a. Hrvatski udio potrošnje biomase u ukupnoj bruto finalnoj potrošnji EU-a manji je od $1 \%$, dok je najveći udio imala Njemačka. Na razini Hrvatske udio potrošnje biomase u ukupnoj bruto finalnoj potrošnji iznosio je 14,7 \%.

Nadalje, prema podatcima Bioenergy Europe (Statistical Report, 2019.) primarna proizvodnja energije iz obnovljivih izvora jedina je kategorija koja se u EU-28 povećava, a glavnu ulogu u tome imaju biomasa i vjetar; biomasa i dalje ima vodeće mjesto (s udjelom od $18 \%$ u proizvodnji primarne energije u EU-28 u 2017.). Stoga su OIE-ovi ključni činitelj za osiguranje energetske neovisnosti EU-a. Doista, u EU-28 primarna se proizvodnja fosilnih goriva drastično smanji- la - za gotovo $50 \%$ u 2017. u usporedbi sa 2000 . godinom. U Hrvatskoj je udio proizvodnje primarne energije iz biomase i obnovljivog otpada u odnosu prema ukupnoj proizvodnji primarne energije iznosio 38,04\% (sl. 2.).

Prema podatcima Europskog vijeća za pelet EPC (akronim od engl. European Pellet Council) objavljenima u izvještaju udruge Bioenergy Europe, većina je zemalja članica EU-a u 2018. iskoristila više od polovice svojih kapaciteta za proizvodnju peleta. Nadalje, prema istom izvještaju, Hrvatska od 2010. bilježi stalan rast proizvodnje peleta, pri čemu su svi tržišni uvjeti postali povoljni (dostupnost sirovina i inozemna potražnja) te omogućuju razvoj proizvodnje, a očekuje se da će se taj rastući trend nastaviti.

Ukupni kapacitet proizvodnje na razini EU-a u 2018. iznosio je 23,4 milijuna tona, a proizvedeno je 16,9 milijuna tona peleta. Iako je najveći broj operativnih pogona za proizvodnju peleta bio u Španjolskoj, najveći kapacitet i ostvarenu proizvodnju imala je Njemačka. Hrvatska je 2018. ostvarila $82 \%$ moguće proizvodnje peleta s obzirom na to da je naš kapacitet proizvodnje bio 370000 tona, a proizvedeno je 305000 tona peleta. Kapaciteti proizvodnje i stvarno ostvarena proizvodnja u zemljama članicama EU-a prikazane su na slici 3. Prema istom izvještaju, u EU-u je 2018. bilo 719 operativnih pogona za proizvodnju peleta, najviše u Španjolskoj, i to 80, dok je Hrvatska imala 21 instalirani pogon za proizvodnju peleta.

Unija još uvijek uvelike ovisi o uvozu goriva, posebice nafte i plina, a ista je situacija i s biomasom. Prema podatcima Eurostata u izvještaju Bioenergy Europe, u EU-u je 2018. ostvaren viši uvoz biomase od izvoza. Nadalje, 2018. godine najveće su izvoznice biomase od zemalja članica EU-a bile Latvija, Estonija i Austrija, dok su UK, Italija i Danska iste godine bile najveće uvoznice. Hrvatska je u području biomase i obnovljivog otpada izvozno orijentirana jer je promatrane godine $u$ 
Biljuš, Basarac Sertić: Potencijal i uloga biomase u hrvatskoj i europskoj energetskoj...

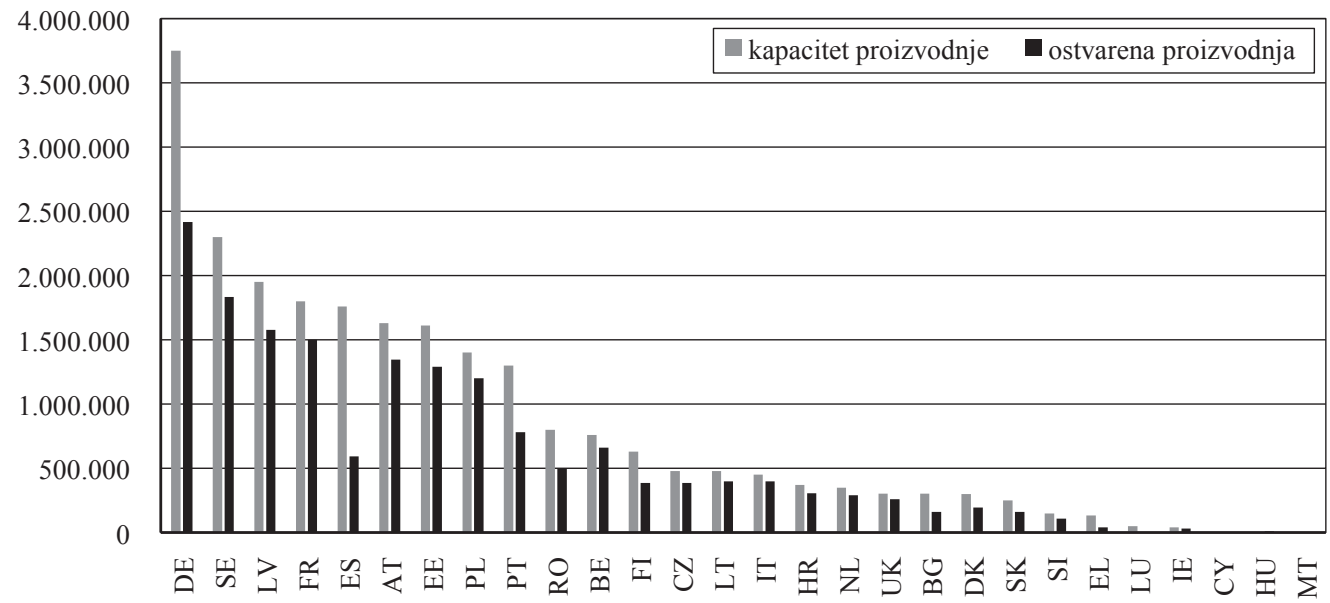

Slika 3. Proizvodnja peleta u EU-28 u 2018. godini, u tonama (European Pellet Council)

Figure 3 Pellet production in tons in 2018 in EU28 (European Pellet Council)

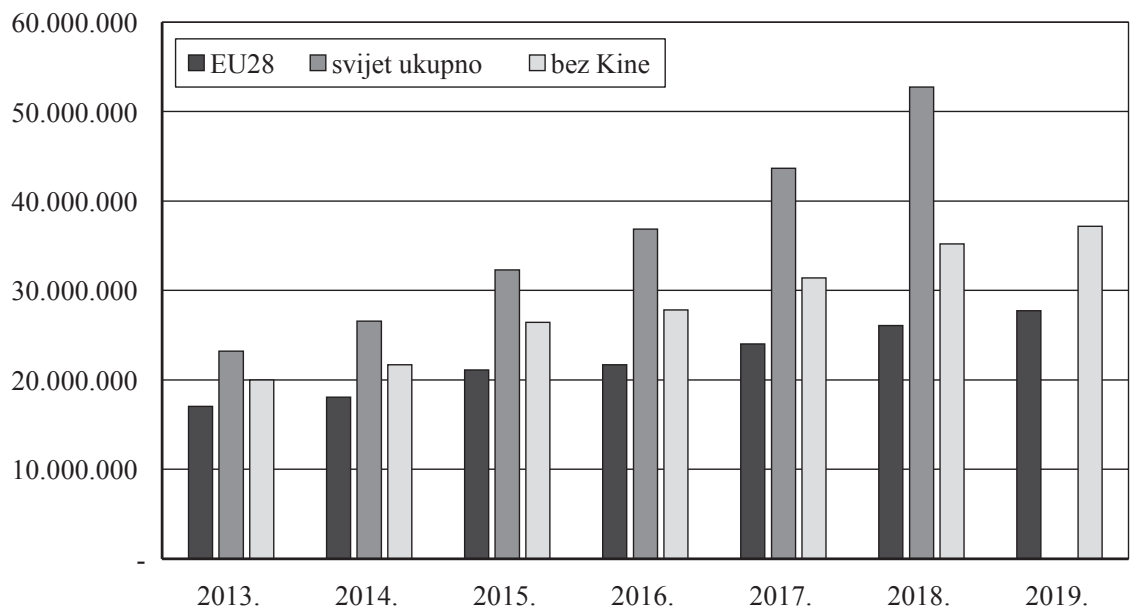

Slika 4. Potrošnja peleta u svijetu u razdoblju 2013. - 2019., u tonama (Bioenergy Europe)

Figure 4 Global pellet consumption between 2013 and 2019, in tonnes (Bioenergy Europe)

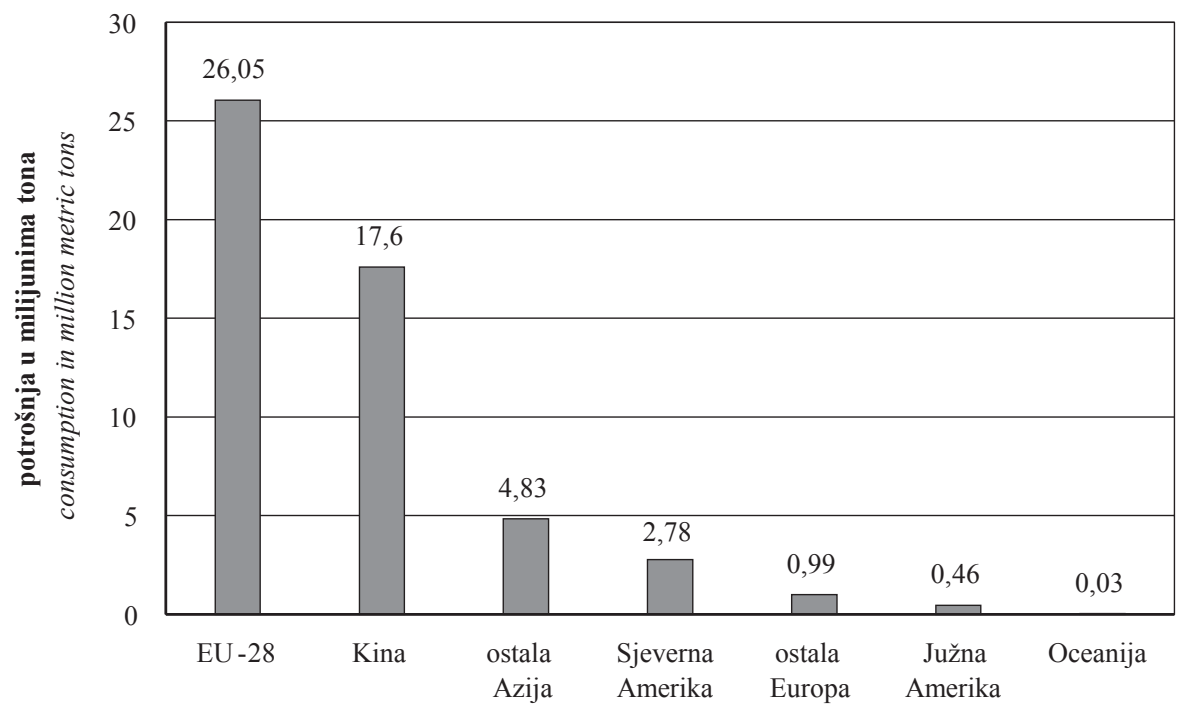

Slika 5. Potrošnja peleta u odabranim regijama svijeta u 2018., u milijunima tona (Statista)

Figure 5 Consumption of wood pellets worldwide in 2018, by select region, in million metric tons (Statista) 


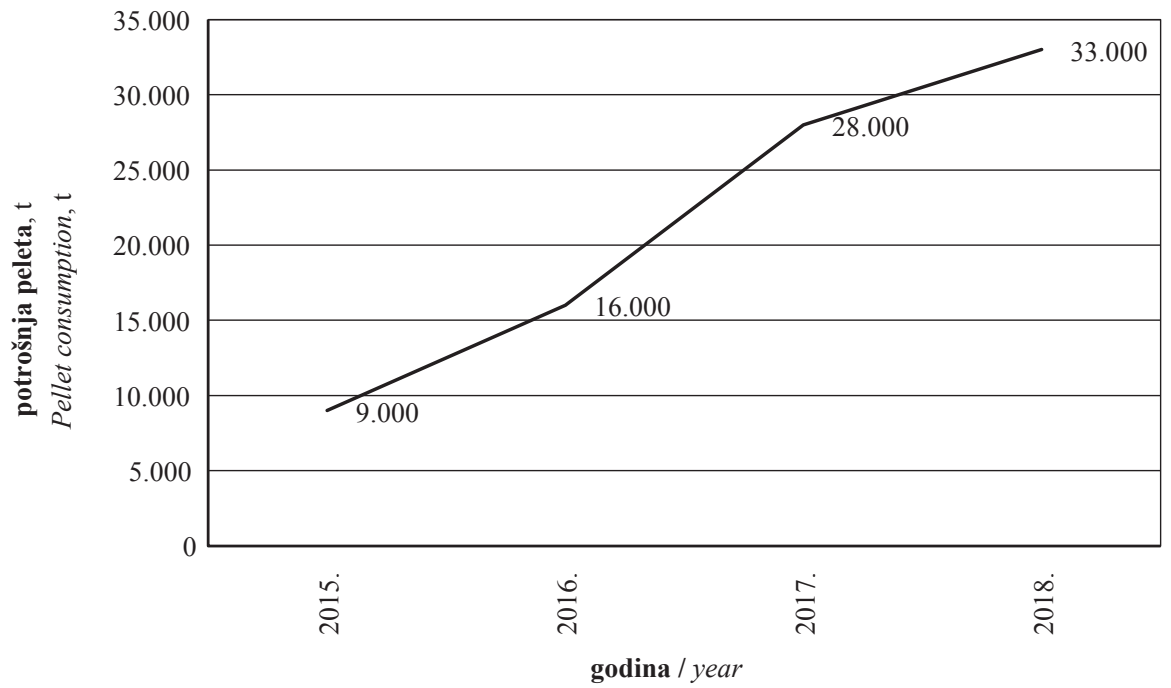

Slika 6. Potrošnja peleta u Hrvatskoj u razdoblju 2013. - 2018., u tonama (Bioenergy Europe)

Figure 6 Pellet consumption in Croatia from 2013 to 2018, in tonnes (Bioenergy Europe)

Hrvatsku uvezeno 29000 tona ekvivalentne nafte, a izvezeno 312000 tona ekvivalentne nafte.

Kada je riječ o globalnoj potrošnji peleta u razdoblju 2013. - 2019., vidljiv je kontinuirani rast (sl. 4.). Nadalje, prema podatcima na slici 5., razvidno je da se velik dio potražnje drvenih peleta u 2018. odnosio na zemlje članice EU-a.

Nadalje, na slici 6. predočena je potrošnja peleta u Hrvatskoj u razdoblju 2015. - 2018., koja prema podatcima Bioenergy Europe bilježi evidentan porast.

Međutim, unatoč porastu potrošnje peleta, i dalje postoji velik potencijal za popularizaciju tog energenta u Hrvatskoj. Stoga je nužno pokrenuti kampanje koje će informirati javnost i educirati društvo o pozitivnim učincima koji proizlaze iz upotrebe peleta. Država može dati primjer poticanjem zelene javne nabave i upotrebom peleta kao energenta među javnim korisnicima, a jedna od mjera za povećanje potrošnje jest i porezno rasterećenje smanjenjem PDV-a na pelete, što bi pozitivno utjecalo i na proizvodnju peleta na domaćem tržištu. Također, za poticanje kućanstava na veću potrošnju peleta potrebno je provoditi projekte dodjele sredstava fizičkim osobama, odnosno građanima za nabavu i ugradnju kotlova i peći na pelete. Kako bi se stimuliralo tržište i povećala proizvodnja i potrošnja peleta, nužno je stvoriti povoljnu investicijsku klimu osiguravanjem subvencija za proizvođače, ali i uklanjanjem zakonodavnih, administrativnih i tehničkih prepreka koje znatno usporavaju i otežavaju ulaganja.

\section{ZAKLJUČAK}

\section{CONCLUSIONS}

U procesu dekarbonizacije gospodarstva i prelaska s fosilnih goriva na OIE-ove, biomasa zbog svoje obnovljivosti i održivosti ima važnu ulogu u energetskoj tranziciji RH. Sagledavanjem okolišnih i ekonomsko-socijalnih učinaka upotrebe biomase kao energenta može se zaključiti da, unatoč manjim negativnim utjecajima na okoliš, biomasa svojim pozitivnim utje- cajem na okoliš, ekosustave i zdravlje ljudi uvelike pridonosi održivom razvoju i postizanju energetskih ciljeva, ali i razvoju hrvatskoga gospodarstva pridonoseći većem zapošljavanju i jačem regionalnom razvoju.

Iako je Hrvatska ostvarila europske ciljeve za potrebnih $20 \%$ udjela proizvodnje iz obnovljivih izvora do 2020., provedenom analizom hrvatskog tržišta biomase može se zaključiti da je udio biomase u proizvodnji iz OIE-ova još uvijek premalen. Nadalje, biomasa kao OIE ima sve veću važnost unutar europskih, ali i nacionalnih zakonodavnih okvira koji prate europske smjernice razvoja. Na temelju provedenog istraživanja može se zaključiti da je jasno vidljiv pomak prema niskougljičnoj energetici, u čemu upravo biomasa ima bitnu ulogu, iako je stopa iskorištavanja biomase u Hrvatskoj još uvijek ispod ambicioznog scenarija koji predviđa EU. Mijenja se javna percepcija o mogućnostima i politikama sektora energije dobivene iz biomase, ali nedovoljnim intenzitetom. Međutim, treba uzeti u obzir činjenicu da je energetska tranzicija dugotrajan proces za koji ne postoje prethodna iskustva na kojima se ona može temeljiti, zbog čega je potrebno kontinuirano pratiti rezultate i dinamiku promjena u idućim godinama. Stoga, unatoč sve većem zanimanju za iskorištavanje biomase kao obnovljivog izvora energije za proizvodnju i potrošnju, i dalje postoji izniman potencijal za napredak i popularizaciju tog energenta $\mathrm{u} \mathrm{Hr}-$ vatskoj.

\section{LITERATURA}

6 REFERENCES

1. Bjerkem, J.; Pilati, M.; Dhéret, C.; Giuli, M.; Šipka, S., 2019: An industry action plan for a more competitive, sustainable and strategic European Union. European Policy Centre. https://wms.flexious.be/editor/plugins/imagemanager/content/2140/PDF/An_industry_action plan-17_01_20.pdf (pristupljeno 10. travnja 2020).

2. Šegon, V.; Šimek, T.; Oradini, A.; Marchetti, M.; Paladinić, E., 2014: Priručnik za učinkovito korištenje biomase. Hrvatski šumarski institut, Zagreb. http://www. 
sumins.hr/wp-content/uploads/2017/08/Prirucnik.Biomasa-hrv.pdf (pristupljeno 10. travnja 2020).

3. ***Bioenergy Europe, 2018: Statistical Report 2018: Full Report. http://achbiom.cl/wp-content/uploads/2019/02/STATISTICAL-REPORT-2018.pdf (pristupljeno 25. studenog 2020).

4. ***Bioenergy Europe, 2019: Statistical Report 2019: Report Bioenergy Landscape.

5. ***Bioenergy Europe, 2019: Statistical Report 2019: Report Pellet. European Pellet Council.

6. ***Bioenergy Europe, 2020: Statistical Report 2020: Report Pellets. European Pellet Council.

7. ***Energetski institut „Hrvoje Požar“, 2019a: Analize i podloge za izradu Strategije energetskog razvoja Republike Hrvatske. Bijela knjiga. Zagreb: Energetski institut „Hrvoje Požar“. https://mzoe.gov.hr/UserDocsImages/ UPRAVA\%20ZA\%20ENERGETIKU/Strategije, \%20 planovi\%20i\%20programi/BIJELA\%20KNJIGA\%20 \%20Analiza\%20i\%20podloge\%20za\%20izradu\%20 Strategije\%20energetskog\%20razvoja\%20Republike\%20Hrvatske.pdf (pristupljeno 10. travnja 2020).

8. ***Energetski institut „Hrvoje Požar“, 2019b: Analize i podloge za izradu Strategije energetskog razvoja Republike Hrvatske. Zelena knjiga. Zagreb: Energetski institut „Hrvoje Požar“. https://mingor.gov.hr/UserDocsImages/ UPRAVA\%20ZA\%20ENERGETIKU/Strategije,\%20 planovi\%20i\%20programi/Analiza\%20i\%20podloga $\% 20$ za $\% 20$ izradu $\% 20$ Strategije $\% 20$ energetskog $\% 20$ razvoja \%20Republike\%20Hrvatske\%20-ZELENA\%20 KNJIGA\%20_kona\%C4\%8Dna\%20verzija\%20(002). pdf (pristupljeno 10. travnja 2020).

9. ***Energetski institut „Hrvoje Požar“, 2019c: Energija u Hrvatskoj - Godišnji energetski pregled. Ministarstvo zaštite okoliša i energetike Republike Hrvatske. http:// www.eihp.hr/wp-content/uploads/2020/04/Energija2018.pdf (pristupljeno 10. travnja 2020).

10. ***EuropaBio, 2016: Jobs and growth generated by industrial biotechnology in Europe. The European Association for Bioindustries. https://www.europabio.org/sites/ default/files/FULL\%20VERSION\%20-\%20IB \%20 Jobs\%20and\%20Growth\%20study_0.pdf (pristupljeno 10. travnja 2020).

11. ***European Biomass Association, 2017: AEBIOM Statistical Report, European Bioenergy Outlook 2016, Full Report.

12. ***European Biomass Association, 2018: AEBIOM Statistical Report, European Bioenergy Outlook 2017, Full Report. https://ibtc.bioenergyeurope.org/wp-content/uploads/2018/08/AEBIOM-2017-STATISTICAL-REPORT.pdf (pristupljeno 25. studenog 2020).

13. ***European Commission, 2010: EUROPE $2020-\mathrm{A}$ strategy for smart, sustainable and inclusive growth. Brussels, 3. 3. 2010. COM(2010) 2020. https://ec.europa. eu/eu2020/pdf/COMPLET\%20EN\%20BARROSO $\% 20$ $\% 20 \% 20007 \% 20-\% 20$ Europe $\% 202020 \% 20-\% 20$ EN\%20version.pdf (pristupljeno 10. travnja 2020).

14. ***European Commission, 2011: A Roadmap for moving to a competitive low carbon economy in 2050. Brussels, 8. 3. 2011. COM(2011) 112 final. https://eur-lex. e u r o p a . e u / L ex UriS erv/Lex U riS erv. do?uri=COM:2011:0112:FIN:EN:PDF (pristupljeno 10. travnja 2020).

15. ***European Commission, 2012: Renewable Energy: a major player in the European energy market. Brussels, 6 . 6. 2012. COM(2012) 271 final. https://eur-lex.europa.eu/ legal-content/EN/TXT/PDF/?uri=CELEX:52012DC027 $1 \&$ from $=\mathrm{EN}$ (pristupljeno 10. travnja 2020).
16. ***European Commission, 2020: A New Industrial Strategy for Europe. COM(2020) 102 final. https://ec.europa.eu/info/sites/info/files/communication-eu-industrial-strategy-march-2020_en.pdf (pristupljeno 10. travnja 2020).

17. ***European Pellet Council, 2020: Report Pellet. Bioenergy Europe. https://epc.bioenergyeurope.org/wp-content/uploads/2020/02/SR19_Pellet_final-web-1.pdf (pristupljeno 10. travnja 2020).

18. ***Europska komisija, 2019: Četvrto izvješće o stanju energetske unije, Bruxelles, 9. 4. 2019. COM(2019) 175 final. https://ec.europa.eu/transparency/regdoc/ rep/1/2019/HR/COM-2019-175-F1-HR-MAIN-PART-1. PDF (pristupljeno 10. travnja 2020).

19. ***Europska komisija, 2015: Paket mjera za Energetsku uniju - Okvirna strategija za otpornu energetsku uniju s naprednom klimatskom politikom. Bruxelles, 25. 2. 2015. COM(2015) 80 final. https://eur-lex.europa.eu/resource.html?uri=cellar: 1 bd46c90-bdd4-11e4-bbe101 aa75ed71a1.0005.02/DOC_1\&format=PDF (pristupljeno 10. travnja 2020).

20. ***Europska komisija, 2016: Čista energija za sve Europljane. Bruxelles, 30. 11. 2016. COM(2016) 860 final. h t t p s : / / e ur-1 ex . europa.eu/resource. html?uri=cellar:d2648a37-c626-11e6-a6db-01aa75ed71a1.0014.02/DOC_1\&format=PDF (pristupljeno 10. travnja 2020).

21. ***Europska komisija, 2017: Izvješće o napretku u području obnovljive energije. Bruxelles, 1. 2. 2017. COM(2017) 57 final. https://eur-lex.europa.eu/LexUriServ/LexUriServ.do?uri=COM:2017:0057:FIN:HR:PDF (pristupljeno 10. travnja 2020).

22. ***Europska komisija, 2018a: Održivo biogospodarstvo za Europu: Jačanje veze gospodarstva, društva i okoliša. Bruxelles, 11. 10. 2018. COM(2018) 673 final. https:// eur-lex.europa.eu/legal-content/HR/TXT/PDF/?uri=CE LEX:52018DC0673\& from=EN (pristupljeno 10. travnja 2020).

23. ***Europska komisija, 2018b: Čist planet za sve - Europska strateška dugoročna vizija za prosperitetno, moderno, konkurentno i klimatski neutralno gospodarstvo. Bruxelles, 28. 11. 2018. COM(2018) 773 final. https:// eur-lex.europa.eu/legal-content/HR/TXT/PDF/?uri=CE LEX:52018DC0773\&from=EN (pristupljeno 10. travnja 2020).

24. ***Europska komisija, 2019a: Europski zeleni plan, Bruxelles, 11. 12. 2019. COM(2019) 640 final. https:// ec.europa.eu/transparency/regdoc/rep/1/2019/HR/COM2019-640-F1-HR-MAIN-PART-1.PDF (pristupljeno 10. travnja 2020)

25. ***Europska komisija, 2019b: Izvješće o napretku u području obnovljive energije, Bruxelles, 9. 4. 2019. COM(2019) 225 final. https://ec.europa.eu/transparency/ regdoc/rep/1/2019/HR/COM-2019-225-F1-HR-MAINPART-1.PDF (pristupljeno 10. travnja 2020).

26. ***Europska komisija, 2019c: Čista energija - Europski zeleni plan. SBN 978-92-76-13947-8 doi:10.2775/546823 NA-02-19-959-HR-N.

27. ***Eurostat, https://ec.europa.eu/eurostat/home? (pristupljeno 10. travnja 2020).

28. ***Ministarstvo gospodarstva, 2013: Nacionalni akcijski plan za obnovljive izvore energije do 2020. godine. https://files.hrote.hr/files/PDF/Dokumenti/NAP/Nacionalni\%20akcijski\%20plan\%20za\%20OIE\%20do\%202020. pdf (pristupljeno 10. travnja 2020).

29. ***Ministarstvo zaštite okoliša i energetike, 2019a: Nacrt prijedloga Strategije energetskog razvoja Republike 
Hrvatske do 2030. s pogledom na 2050. godinu [online]. Zagreb, Ured za zakonodavstvo Vlade Republike Hrvatske. https://esavjetovanja.gov.hr/Econ/MainScreen? EntityId=10936 (pristupljeno 10. travnja 2020).

30. ***Ministarstvo zaštite okoliša i energetike, 2019b: Strateška studija procjene utjecaja na okoliš za Strategiju energetskog razvoja Republike Hrvatske do 2030. godine s pogledom na 2050. godinu. Treća inačica, Zagreb, svibanj 2019. https://mzoe.gov.hr/UserDocsImages/UPRAVA\%20ZA\%20ENERGETIKU/Strategije,\%20planovi $\% 20 \mathrm{i} \% 20$ programi/Strate $\%$ C5\%A1 ka $\% 20$ studija $\% 20$ procjene $\% 20$ utjecaja $\% 20$ na $\% 20$ okoi $\%$ C5 $\%$ A 1 i $\% 20$ za\%20Strategiju\%20energetskog\%20razvoja\%20 RH $\% 20 \% 20$ do $\% 202030 \% 20$ s $\% 20$ pogledom $\% 20$ na $\% 20$ 2050.\%20god.-Tre\%C4\%87a\%20ina\%C4\%8Dica.pdf (pristupljeno 10. travnja 2020).

31. ***Ministarstvo zaštite okoliša i energetike, 2019c: Integrirani nacionalni energetski i klimatski plan za Republiku Hrvatsku za razdoblje od 2021. do 2030. godine, prosinac 2019. https://mzoe.gov.hr/UserDocsImages// UPRAVA\%20ZA\%20ENERGETIKU/Strategije, \%20 planovi $\% 20 \mathrm{i} \% 20$ programi/hr\%20necp//Integrirani $\% 20$ nacionalni $\% 20$ energetski $\% 20 \mathrm{i} \% 20 \mathrm{klimatski} \% 20$ plan\%20Republike $\% 20$ Hrvatske $\% 20 \% 20$ final.pdf (pristupljeno 10. travnja 2020).

32. ***Ministarstvo zaštite okoliša i energetike, 2019c: Integrirani nacionalni energetski i klimatski plan za Republiku Hrvatsku za razdoblje od 2021. do 2030. godine. https://mzoe.gov.hr/UserDocsImages//UPRAVA\%20 ZA\%20ENERGETIKU/Strategije,\%20planovi\%20i\%20 programi/hr\%20necp//Integrirani\%20nacionalni\%20energetski\%20i\%20klimatski\%20plan\%20Republike $\% 20$ Hrvatske\%20\%20_final.pdf (pristupljeno 10. travnja 2020).

33. ***Narodne novine, 2001: Zakon o energiji. Zagreb: Narodne novine d.d., NN 68/2001 https://narodne-novine.nn.hr/clanci/sluzbeni/2001_07_68_1120.html (pristupljeno 10. travnja 2020).

34. ***Narodne novine, 2002: Strategija energetskog razvitka Republike Hrvatske. Zagreb: Narodne novine d.d., NN 38/2002. https://narodne-novine.nn.hr/clanci/sluzbeni/2002_04_38_839.html (pristupljeno 10. travnja 2020).

35. ***Narodne novine, 2004: Zakon o izmjenama i dopunama Zakona o energiji. Zagreb: Narodne novine d.d., NN 177/2004. https://narodne-novine.nn.hr/clanci/sluzbeni/2004_12_177_3079.html (pristupljeno 10. travnja 2020).

36. ***Narodne novine, 2009: Strategija energetskog razvoja Republike Hrvatske. Zagreb: Narodne novine d.d., NN 130/2009. https://narodne-novine.nn.hr/clanci/sluzbeni/2009_10_130_3192.html (pristupljeno 10. travnja 2020).

37. ***Narodne novine, 2012: Zakon o energiji. Zagreb, Narodne novine d.d., NN 120/2012. https://narodne-novine.nn.hr/clanci/sluzbeni/2012_10_120_2583.html (pristupljeno 10. travnja 2020).

38. ***Narodne novine, 2015: Zakon o drvenastim kulturama kratkih ophodnji. Zagreb: Narodne novine d.d., NN 15/2018. https://narodne-novine.nn.hr/clanci/sluzbeni/ 2018_02_15_313.html (pristupljeno 10. travnja 2020).
39. ***Narodne novine, 2015: Zakon o obnovljivim izvorima energije i visokoučinkovitoj kogeneraciji. Zagreb: Narodne novine d.d., NN 100/2015. https://narodne-novine.nn.hr/clanci/sluzbeni/2015_09_100_1937.html (pristupljeno 10. travnja 2020).

40. $* * *$ Narodne novine, 2016: Strategija pametne specijalizacije Republike Hrvatske za razdoblje od 2016. do 2020. godine i Akcijski plan za provedbu strategije pametne specijalizacije Republike Hrvatske za razdoblje od 2016. do 2017. godine. Zagreb: Narodne novine d.d., NN 32/2016. https://narodne-novine.nn.hr/clanci/sluzbeni/dodatni/439965.pdf (pristupljeno 10. travnja 2020).

41. ***Narodne novine, 2018: Zakon o izmjenama i dopunama Zakona o obnovljivim izvorima energije i visokoučinkovitoj kogeneraciji. Zagreb: Narodne novine d.d., NN 111/2018. https://narodne-novine.nn.hr/clanci/ sluzbeni/2018_12_111_2151.html (pristupljeno 10 . travnja 2020).

42. ***Narodne novine, 2020: Strategija energetskog razvoja Republike Hrvatske do 2030. s pogledom na 2050. godinu. Zagreb: Narodne novine d.d., NN 25/2020-602, https://narodne-novine.nn.hr/clanci/sluzbeni/2020_ 03_25_602.html (pristupljeno 10. travnja 2020).

43. ***S Službeni list Europske unije, 2009: Direktiva 2009/28/EZ Europskog Parlamenta i Vijeća od 23. travnja 2009. o promicanju uporabe energije iz obnovljivih izvora te o izmjeni i kasnijem stavljanju izvan snage direktiva 2001/77/EZ i 2003/30/EZ. https://eur-lex.europa. eu/legal-content/HR/TXT/PDF/?uri=CELEX:32009L00 28\&from=HR (pristupljeno 10. travnja 2020).

44. ***Službeni list Europske unije, 2014: Mišljenje Odbora regija - Okvir za klimatsku i energetsku politiku u razdoblju 2020. - 2030., 2014/C 415/04. https://eur-lex.europa.eu/legal-content/HR/TXT/PDF/?uri=CELEX:5201 4IR2691\& from=HR (pristupljeno 10. travnja 2020).

45. ***Službeni list Europske unije, 2018: Direktiva (EU) 2018/2001 Europskog Parlamenta i Vijeća od 11. prosinca 2018. o promicanju uporabe energije iz obnovljivih izvora. https://eur-lex.europa.eu/legal-content/HR/TXT/ PDF/?uri=CELEX:32018L2001\&from=EN (pristupljeno 10. travnja 2020).

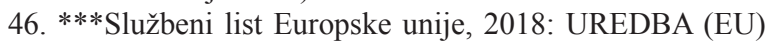
2018/1999 Europskog Parlamenta i Vijeća od 11. prosinca 2018. o upravljanju energetskom unijom i djelovanjem u području klime. https://eur-lex.europa.eu/legalcontent/HR/TXT/PDF/?uri=CELEX:32018R1999 (pristupljeno 10. travnja 2020).

47. ***Statista. https://www.statista.com/statistics/473246/ worldwide-wood-pellet-consumption-by-major-region/.

\section{Corresponding address:}

dr. sc. MARTINA BASARAC SERTIĆ

Hrvatska akademija znanosti i umjetnosti Odsjek za ekonomska istraživanja Hebrangova 1, 10000 Zagreb, CROATIA e-mail: mbasarac@hazu.hr 